\title{
BILATERAL SERRATUS ANTERIOR PLANE CATHETERS IN A POLYTRAUMA PATIENT
}

A. Tay ${ }^{1}$, I. Sinha² , B. Bellew1

${ }^{1}$ St Mary's Hospital- Imperial College Healthcare NHS Trust, Department of Anaesthesia, London, United Kingdom.

2St Mary's Hospital- Imperial College Healthcare NHS Trust, Department of Trauma and Orthopaedics, London, United Kingdom.

Rib fracture pain is severe and traditionally treated with systemic analgesics or epidural block. Opiate analgesics and continuous epidural anaesthesia are commonly associated with side effects. Coagulation abnormalities may prevent catheter insertion. Ultrasound-guided (USG) Serratus Anterior Plane Block (SAPB) and catheter (SAPC) has been shown to provide good analgesia for acute post-thoracotomy pain 1,2 .

A 50-year-old man fell from a height of 2 stories. He sustained multiple rib fractures bilaterally, with a flail segment on the right and bilateral pnuemothoraces. Other injuries included unstable pelvic fractures, right renal laceration and right forearm fractures. Severe rib fracture pain was inadequately controlled by opiates. He was unable to be positioned for an epidural due to his unstable pelvic fractures.

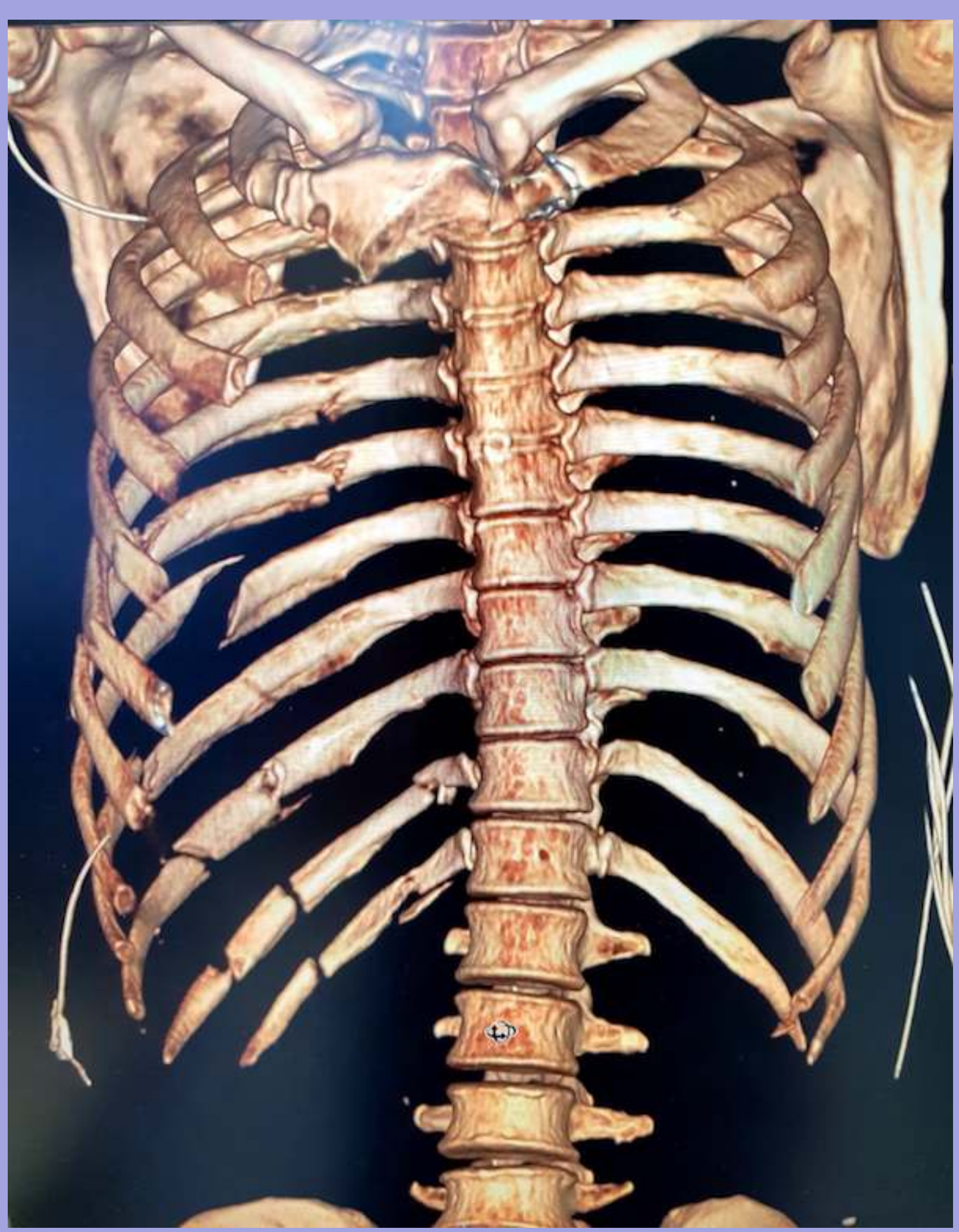

Bilateral USG SAPB were undertaken with $40 \mathrm{mls}$ of $0.125 \%$ bupivacaine $(1: 400,000$ Adrenaline) per side with good effect in the emergency department. Bilateral SAPC were sited and each connected to a continuous infusion of $0.125 \%$ bupivacaine at a rate of $10 \mathrm{ml} / \mathrm{hr}$. He was prescribed paracetamol and oromorph for his other injuries.

He was comfortable on this infusion until the next day when he required 1 bolus of $20 \mathrm{mls}$ of $0.125 \%$ bupivacaine on the right and an increase in infusion rate to $15 \mathrm{ml} / \mathrm{hr}$ on the right and $12 \mathrm{ml} / \mathrm{hr}$ on the left. On the second post-injury day, he had a further bolus of $10 \mathrm{mls}$ of $0.125 \%$ bupivicaine with good effect. Bilateral SAPC infusion maybe a useful alternative to epidural infusion in patients with bilateral rib fractures that are unable to be positioned for epidural catheter insertion.

References:

1. Blanco R, Parras T, McDonnell JG, Prats-Galino A. Serratus plane block: a novel ultrasound-guided thoracic wall nerve block. Anaesthesia 2013; 68:11071113.

2. Khalil AE, Abdallah NM, Bashandy GM, Kaddah TAH. Ultrasound-Guided Serratus Anterior Plane Block Versus Thoracic Epidural Analgesia for Thoracotomy Pain. J. Cardiothorac Vasc Anesth 2017,31:152-158. 